Article

\title{
Cylindrical IR-ATR Sensors for Process Analytics
}

\author{
Armin Lambrecht *, Carsten Bolwien, Jochen Erb, Hendrik Fuhr and Gerd Sulz \\ Fraunhofer IPM, Heidenhofstr. 8, D-79110 Freiburg, Germany; carsten.bolwien@ipm.fraunhofer.de (C.B.); \\ jochen.erb@ipm.fraunhofer.de (J.E.); hendrik.fuhr@ipm.fraunhofer.de (H.F.); gerd.sulz@ipm.fraunhofer.de (G.S.) \\ * Correspondence: armin.lambrecht@ipm.fraunhofer.de; Tel.: +49-761-8857-122
}

Received: 25 April 2020; Accepted: 19 May 2020; Published: 21 May 2020

\begin{abstract}
Infrared attenuated total reflection (ATR) spectroscopy is a common laboratory technique for the analysis of highly absorbing liquids and solids. However, in a process environment, maintaining a sufficient sample exchange and cleaning of the sensitive surface of the element is a crucial issue. An important industrial application is the measurement of isocyanate concentrations. Isocyanates are necessary for the fabrication of polyurethane materials and are among the chemicals with the highest production volume worldwide. For process applications, narrowband photometers or MEMS spectrometers are more appropriate than the use of bulky FTIR instruments frequently encountered in a laboratory environment. Toluene diisocyanate (TDI) and hexamethylene diisocyanate (HDI) concentrations are measured with a planar ATR photometer setup. Using a miniature Fabry-Perot interferometer (FPI), trace concentrations below $100 \mathrm{ppm}(\mathrm{m} / \mathrm{m})$ are detected. By employing an ATR element of the cylindrical shape, sensors can be realized with a smooth surface ideally suited for an automatic cleaning system in a process environment. A laboratory setup with sapphire tubes as ATR elements for incorporation in a liquid flow system is described. Reflection and transmission configurations were investigated. Measurements with acetonitrile as a less toxic substitute showed that with cylindrical ATR sensors' detection limits for isocyanate concentrations below $100 \mathrm{ppm}$ $(\mathrm{m} / \mathrm{m})$ are feasible.
\end{abstract}

Keywords: infrared spectroscopy; ATR (attenuated total reflection); PAT (process analytical technology); inline; online; isocyanate; acetonitrile; sapphire; photometer; miniature spectrometer

\section{Introduction}

Infrared attenuated total reflection (ATR) spectroscopy is a common technique for the analysis of highly absorbing liquids and solids. When a radiation wave in an optical material is totally reflected at an interface with a material of lower index of refraction, part of the wave penetrates into the sample. The penetration depth of this evanescent wave, i.e., the probed sample thickness, is approximately equal to the radiation wavelength $\lambda_{s}$ in the sample [1,2]. In the mid-infrared (MIR) range $(3<\lambda$ $<20 \mu \mathrm{m}$ ), this is only a few $\mu \mathrm{m}$. The ATR technique has found widespread applications, e.g., in medical diagnostics [3,4], food quality analysis [5], beverage industry [6,7], water contamination monitoring [8,9], determination of moisture in the transformer and lubrication oil [10], pharmaceutical process analytics [11], and monitoring of rubber polymerization [12].

However, usually, ATR spectroscopy is mainly used in a laboratory environment. ATR attachments are available for most Fourier transform infrared (FTIR) spectrometers, e.g., [13]. In this case, samples are often manually placed on top of or, in the case of solid samples, pressed onto a suitable ATR crystal surface. Immersion ATR probes for the spectroscopy of liquids, e.g., in a laboratory reactor, are also available [14-16]. Usually, they consist of infrared light guides or fibers, which are connected to an ATR prism at the tip of the probe.

Surface contamination or residuals on the ATR element will cause erroneous results. Thus, careful cleaning and/or rinsing of the surface between different samples is necessary. If ATR sensors are used 
with flowing media, sufficient exchange at the surface has to be ensured. If such a device is applied in an industrial online or inline configuration, it is placed close to a product-carrying tube or vessel in a production environment, where manual cleaning is hardly possible. This is, e.g., the case for the beverage industry, where process sensors have to cope with established cleaning in place (CIP) systems [6,7]. For typical prism tip probes, automatic cleaning is not easy [17]. Even with a flat ATR crystal, optimum packaging of the element is crucial to avoid sharp edges and undercuts where sample flow may be constrained, and fouling may occur. Wiping and liquid cleaning would be easier for smooth cylindrical ATR surfaces.

Additionally, a process sensor has to be very robust and comply with all the required safety regulations. Therefore, narrowband photometers or miniature MEMS spectrometers are more appropriate than the use of FTIR instruments generally encountered in a laboratory environment. They are also a key component for small portable ATR sensors [18].

An important industrial application is the measurement of isocyanate concentrations. Isocyanates are necessary for the fabrication of polyurethane (PU) materials, and are among the chemicals with the highest production volumes worldwide. PU materials are utilized for coatings, construction foams, mattresses, shoes, automotive components, and many other products. Laboratory measurements of isocyanate reactions using fiberoptic probes are reported in $[19,20]$. The infrared spectra of isocyanates are dominated by a characteristic absorption of the NCO-stretching vibration around $2270 \mathrm{~cm}^{-1}$. Fortunately, in this spectral region, features of other components in a mixture, e.g., solvents, are hardly observed. Thus, for the determination of isocyanate concentrations, the measurement with a two-channel photometric detector can be sufficient. By the selection of suitable filters, one detection channel is positioned at the NCO band, and the other channel serves as a reference placed at a spectral position with no isocyanate absorption. However, as the shape and position of individual isocyanates differ, and the change of solvents and other components may introduce a varying background, spectral measurements with a sufficient bandwidth and resolution are preferred. A microspectrometer based on a Fabry-Perot interferometer (FPI) can fulfil this task.

In this work, the BASF product Basonat HI100 (trimerized hexamethylene diisocyanate (HDI), with propylene carbonate and isopropanol as solvents was used. In addition, some experiments were performed with toluene 2,4-diisocyanate (TDI) in monochlorobenzene (MCB). Both isocyanates were used for experiments with planar ATR elements. They are highly toxic chemicals, e.g., the OSHA personal exposure limit of TDI is $5 \mathrm{ppb}$ [21]. Therefore, we were looking for a nontoxic alternative for the spectroscopic test of different ATR setups in the laboratory. Acetonitrile (AC) was identified as a suitable material with good solubility in isopropanol and/or water. Thus, experiments with cylindrical ATR elements were performed with acetonitrile in isopropanol.

This paper is organized as follows. Starting with planar ATR configurations, Section 2 describes an ATR photometer setup and the corresponding measurements with isocyanate solutions, followed by a modified setup with an MEMS microspectrometer and experiments with Basonat in propylene carbonate. Finally, with a similar planar configuration coupled to an FTIR instrument, the ATR spectra of $\mathrm{CO}_{2}$ gas, isocyanate, and acetonitrile solutions were obtained. These provide a reference for the analysis of the following results on cylindrical ATR sensors. Section 3 introduces the concept and realization of ATR setups with sapphire tubes as ATR elements. In Section 4, the experimental results with those setups are presented, followed by a discussion of the obtained data in Section 5 and a comparison to the results on planar ATR configurations. Section 6 concludes and gives an outlook on future developments.

\section{Planar ATR Sensors}

\subsection{Results on Isocyanate Solutions Using a Planar ATR Photometer}

The use of an ATR photometer for isocyanate concentration determination was previously demonstrated in a non-English publication [22]. As our work is based on these earlier results, the setup is briefly described here. 
The sensor consists of a thermal infrared emitter (micro light bulb from MGG, Wentorf, Germany in [22], later setup: IR-emitter JSIR350-5-BL-R-D3.6-2-A4, Micro-Hybrid Electronic GmbH, Hermsdorf, Germany), a sapphire ATR crystal, and a dual-band pyroelectric detector to register radiation in a spectral window around the main absorption band of the analyte (sample channel) and a reference channel in a spectral window with negligible sample absorption. For optimum light throughput in the crystal, additional coupling optics is employed. The pyrodetector in [22] is an LMM-242 detector from InfraTec $\mathrm{GmbH}$, Dresden, Germany with two spectral filters integrated in a TO8-mount (Table 1). The sapphire element is $32.5 \mathrm{~mm}$ long and $10 \mathrm{~mm}$ wide. A thickness of $1 \mathrm{~mm}$ yields 9 reflections in the mid infrared (MIR) range on the sample side of the crystal. The result of a typical measurement is the ratio of the two detector voltages $\mathrm{V}_{\text {signal }} / \mathrm{V}_{\text {reference. The signal acquisition electronics converts }}$ these voltages to counts/s, which are e.g., displayed in Section 4 (Figures 7-10). As the radiation source is operated with a low frequency modulation below $4 \mathrm{~Hz}$, a narrow band lock-in detection scheme is employed.

Table 1. IR filters and detectors used for planar and cylindrical photometer configurations. The filters were supplied and integrated by InfraTec $\mathrm{GmbH}$ into the detector housings. Data are typical datasheet values from InfraTec $\mathrm{GmbH}$.

\begin{tabular}{cccccc}
\hline Filter-No.: & $\begin{array}{c}\text { Planar (P) or } \\
\text { Cylindrical (C) Use }\end{array}$ & $\begin{array}{c}\text { Center } \\
\text { Wavenumber } \\
\mathbf{( C W L )} \\
/ \mathbf{c m}^{-1}\end{array}$ & $\begin{array}{c}\text { Half Power } \\
\text { Bandwidth } \\
\mathbf{( H P B W )} \\
/ \mathbf{c m}^{-1}\end{array}$ & $\begin{array}{c}\text { Peak } \\
\text { Transmittance } \\
/ \%\end{array}$ & $\begin{array}{c}\text { Detector Type } \\
\text { (Element Size) }\end{array}$ \\
\hline 1 & P-signal\#1 [22] & 2350 & 100 & 81 & $\begin{array}{c}\text { LMM-242 } \\
\left(2 \times 2 \mathbf{m m}^{2}\right)\end{array}$ \\
\hline 2 & P-signal\#2 [22] & 2345 & 330 & 90 & LMM-242 \\
\hline 3 & P-reference\#1\&\#2 [20] & 2530 & 60 & 88 & LMM-242 \\
\hline 4 & C-signal CO 2 & 2342 & 93 & 88 & $\begin{array}{c}\text { LRM-202 } \\
\left(1.2 \times 0.8 \text { mm }^{2}\right)\end{array}$ \\
\hline 5 & C-reference CO $\mathrm{CO}_{2}$ & 2532 & 58 & 83 & LRM-202 \\
\hline 6 & C-signal acetonitrile & 2257 & 138 & 90 & $\begin{array}{c}\text { LRM-254 } \\
\left(1.4 \times 1.4 \mathrm{~mm}^{2}\right)\end{array}$ \\
\hline 7 & C-reference acetonitrile & 2532 & 58 & 84 & LRM-254 \\
\hline
\end{tabular}

Throughout this paper, dealing with spectroscopic and photometric data, we use absorbances calculated as the negative base-10-logarithm of the ratio of sample signals and reference signals. These signals may be measurements at a specific wavelength in spectroscopic data or integrated signals from photometric setups. For photometers, positive or negative absorbance values may occur, depending on, e.g., the employed filters. The resulting absorbances will be marked with the dimensionless unit AU or milli-AU (mAU) for absorbance units. Absorbance changes $\Delta \mathrm{A}$, e.g., between the absorbance of a pure solvent and of a sample solution, should be approximately proportional to the concentration.

Originally, the setup was designed to measure the $\mathrm{CO}_{2}$ content in beverages (Figure 1) [7], and a narrow bandpass filter (\#1 s. Table 1) was employed for the signal channel. However, this filter only covers a small part of the isocyanate band, resulting in low signal voltages. With a broader bandpass (\#2 s. Table 1), the isocyanate band was completely covered. A Varivent DN60 flange, common in beverage industry installations, was employed. The crystal was sealed with Teflon into the flange, and by a force-locked support it was integrated into a pressure-resistant enclosure.

In [22], a corresponding sensor setup was used for laboratory measurements at BASF. A cap on the sensor flange served as a flow cell, and solvents spiked with varying isocyanate concentrations were continuously pumped through this cell. As a result, with this photometric setup, the HDI and TDI concentrations in propylene carbonate respectively in MCB could be measured over the full concentration range from $0 \%$ to $100 \%$. 
For HDI, the BASF product Basonat HI 100 in propylene carbonate was used. For a $4600 \mathrm{ppm}(\mathrm{m} / \mathrm{m})$ solution, an absorbance change $\triangle \mathrm{A}$ of $7.05 \mathrm{mAU}$ is determined from Figure 8 in [22]. The standard deviation $\sigma$ for an average time of $1 \mathrm{~min}$ is approximately $0.14 \mathrm{mAU}$. A noise equivalent concentration $(\mathrm{NEC})(1 \sigma) \approx 91 \mathrm{ppm}(\mathrm{m} / \mathrm{m})$ indicates that a limit of detection below $200 \mathrm{ppm}(\mathrm{m} / \mathrm{m})$ is feasible.

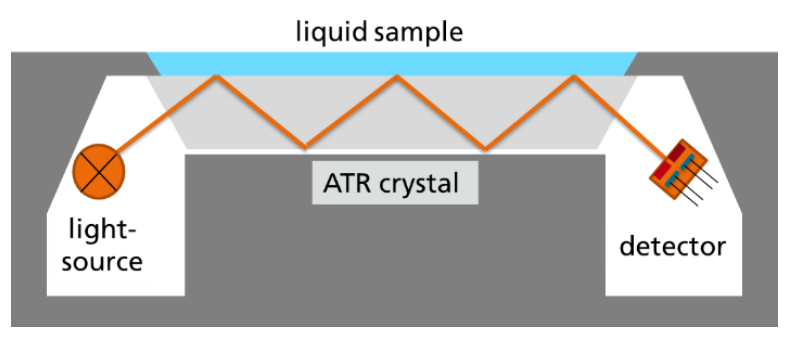

(a)

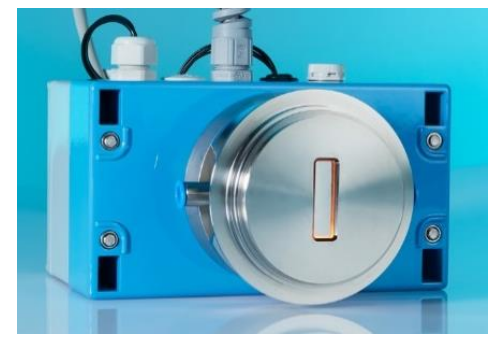

(b)

Figure 1. (a) Concept of a liquid sensor using a planar ATR element [22] and (b) picture of a later industrial sensor system for $\mathrm{CO}_{2}$ measurements in beverag.es.

Using the broader bandpass filter for TDI in MCB, a limit of detection (LOD) below 100 ppm $(\mathrm{m} / \mathrm{m})$ was estimated with an average time of $1 \mathrm{~min}$ [22]. A closer look at these data shows that a $100 \mathrm{ppm}(\mathrm{m} / \mathrm{m})$ solution yields an absorbance change $\Delta \mathrm{A}$ of $3.7 \mathrm{mAU}$ with a standard deviation of $\sigma \approx 1.7 \mathrm{mAU}$. In this case, an NEC $(1 \sigma) \approx 46 \mathrm{ppm}(\mathrm{m} / \mathrm{m})$ indicated that a limit of detection below $100 \mathrm{ppm}(\mathrm{m} / \mathrm{m})$ is feasible for TDI. However, longer averaging was not feasible with this setup because temperature changes induced signal drifts, and stable operation over more than $10 \mathrm{~min}$ was hardly possible. Further details can be found in [22].

\subsection{Results on Isocyanate Solutions Using a Planar ATR Sensor with a FPI Microspectrometer}

Later, drift was effectively reduced by a more rigid mechanical design and compensation by additional temperature sensors. The sapphire crystal has the same dimensions and number of reflections. The setup now uses an FPI microspectrometer (InfraTec LFP-3850C-337) and records a spectrum with 121 spectral data points between 2000 and $2632 \mathrm{~cm}^{-1}$ in approximately $150 \mathrm{~s}$ with the chosen parameters. The performance was evaluated with Basonat solutions in a variety of concentrations between 0 and $10,000 \mathrm{ppm}(\mathrm{m} / \mathrm{m})$ in propylene carbonate. Figure 2 shows the absorbance spectra of $0(\mathrm{~m} / \mathrm{m}), 100(\mathrm{~m} / \mathrm{m})$, and $1000 \mathrm{ppm}(\mathrm{m} / \mathrm{m})$ solutions, calculated from single-channel spectra with pure propylene carbonate as the reference. Each spectrum was smoothed with a 10-point moving average filter to clearly reveal the amplitude of the Basonat absorption around $2260 \mathrm{~cm}^{-1}$ and baseline corrected for clarity. In order to evaluate a quantification from those data, we performed a linear fit based on an average 10,000 ppm $(\mathrm{m} / \mathrm{m})$ spectrum on each of those spectra. Figure $2 \mathrm{~b}$ shows the resulting peak heights plotted against time. The shown excerpt demonstrates distinct absorbance changes when switching from 0 to $100 \mathrm{ppm}$ $(\mathrm{m} / \mathrm{m})$, and gives a noise equivalent concentration estimate (NEC $(1 \sigma))$ of around $25 \mathrm{ppm}(\mathrm{m} / \mathrm{m})$ Basonat for the 150-s-spectra (calculation based on the $100 \mathrm{ppm}(\mathrm{m} / \mathrm{m})$ measurements (NECs for the other concentrations vary slightly due to non-linearity). The test series was performed over ca. $5 \mathrm{~h}$ showing no critical drift or deteriorations, demonstrating the improved stability of the setup.

\subsection{FTIR Reference Spectra with a Planar ATR Element}

For the initial tests of new ATR setups, non-toxic and easy to handle materials with similar spectral features as isocyanate solutions are advantageous. Pressurized $\mathrm{CO}_{2}$ could be used at first hand; however, its spectral features are slightly off the isocyanate absorption peak. Compared to liquid samples, it can be rapidly exchanged to non-absorbing $\mathrm{N}_{2}$, and fast pressure changes are easy to achieve. However, the refractive index is similar to air and much different from the solvents we used 
for the isocyanate samples. Acetonitrile is a better alternative. It is not very toxic and mixing with propylene carbonate and isopropanol is possible.

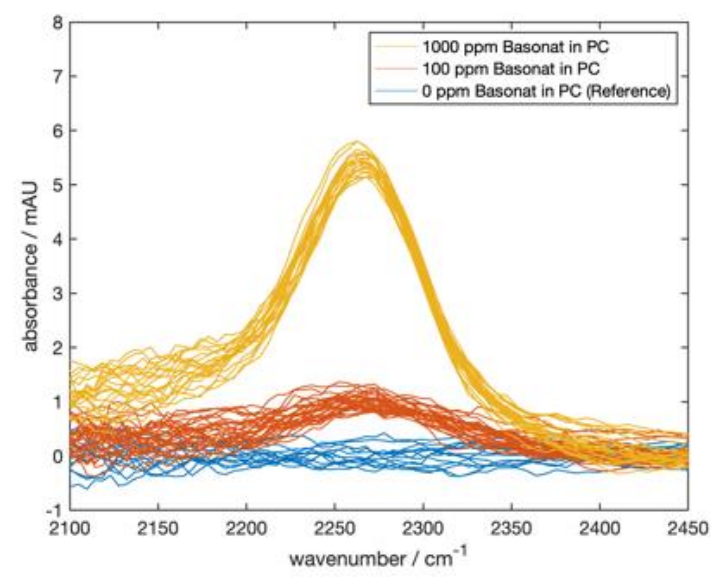

(a)

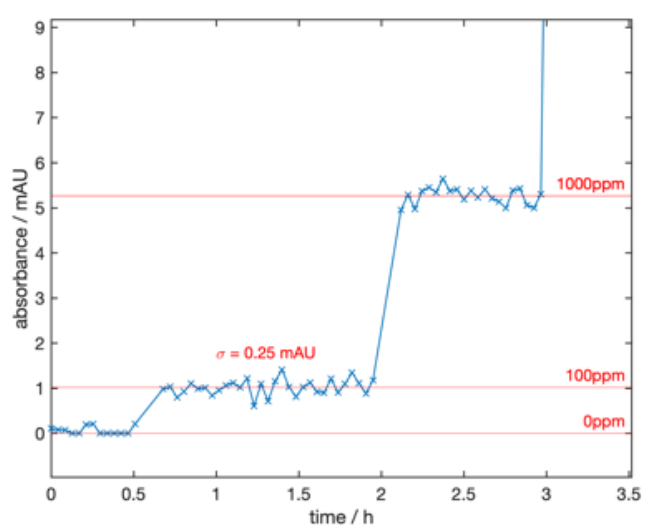

(b)

Figure 2. (a): FPI spectra of Basonat solutions in propylene carbonate (PC) using the planar ATR setup. Each spectrum was recorded within $150 \mathrm{~s}$ and smoothed with a moving average filter. (b) Concentration steps derived from (a) by a linear fit procedure based on an averaged 10,000 ppm (m/m) spectrum. The total measurement duration was around $5 \mathrm{~h}$ (including a 10,000 ppm (m/m) solution not shown here).

To obtain comparable ATR spectra over a broad spectral range and good resolution, a Varivent flange of a process device was equipped with a ZnSe crystal and coupled to an Alpha FTIR spectrometer (Bruker Optik GmbH, Ettlingen, Germany) (Figure 3a). With this setup, 11 ATR reflections were achieved. The spectral resolution was $2 \mathrm{~cm}^{-1}$. From the spectra displayed in Figure $3 \mathrm{~b}$, the relations shown in Table 2 were obtained. Obviously, TDI in MCB has the strongest absorption compared to the other materials. For a 1-min integration time (i.e., 48 spectral scans), a standard deviation of $\sigma \approx 0.3 \mathrm{mAU}$ was determined.

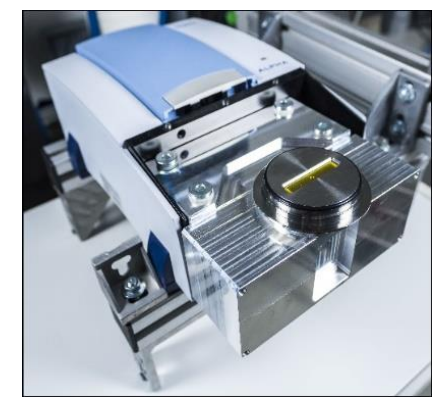

(a)

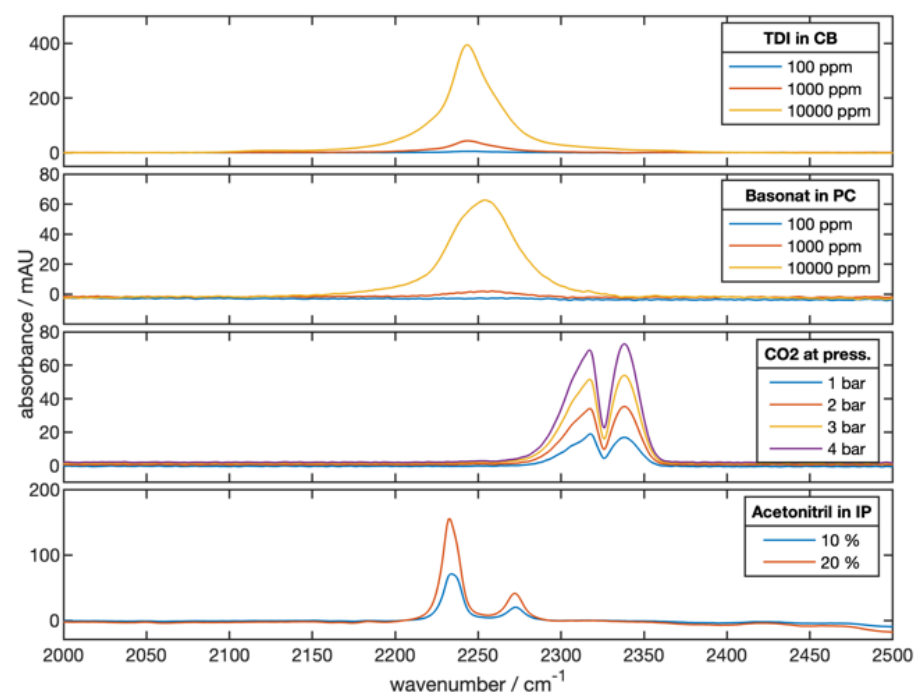

(b)

Figure 3. (a) Planar ATR element with Varivent flange coupled to a Bruker Alpha FTIR instrument. The system can be attached to a liquid or gas flow system capable for pressure levels of up 5 bar. (b) Measured ATR spectra of TDI in MCB, Basonat in propylene carbonate (PC), gaseous $\mathrm{CO}_{2}$, and acetonitrile in isopropanol (IP). 
Table 2. Peak absorbances of sample spectra from Figure $3 b$. Values for the second maxima are in brackets. The relative absorption strength is calculated for the main peaks.

\begin{tabular}{|c|c|c|c|c|c|}
\hline Sample & $\begin{array}{c}\text { Spectral } \\
\text { Position of } \\
\text { Maximum } \\
\text { Absorbance/cm }\end{array}$ & $\begin{array}{l}\text { Full Width at } \\
\text { Half } \\
\text { Maximum } \\
(\text { FWHM)/cm } \\
-1\end{array}$ & $\begin{array}{c}\text { Absorbance at } \\
\text { Spectral Position } \\
\text { of Maximum } \\
\text { Absorbance/mAU }\end{array}$ & $\begin{array}{c}\text { Maximum } \\
\text { Absorbance } \\
\text { for } 1 \%(\mathrm{~m} / \mathrm{m}) \\
\text { Solution Resp. } \\
1 \text { Bar Pressure } \\
\text { of } \mathrm{CO}_{2} / \mathrm{mAU}\end{array}$ & $\begin{array}{c}\text { Relative } \\
\text { Absorption } \\
\text { Strength } \\
\text { Compared to } \\
\text { Acetonitrile in } \\
\text { Isopropanol }\end{array}$ \\
\hline $\begin{array}{l}\text { Acetonitrile in } \\
\text { isopropanol }\end{array}$ & $2230(2270)$ & $20(13)$ & $\begin{array}{c}155(41) \text { for } 20 \% \\
(\mathrm{~m} / \mathrm{m})\end{array}$ & 7.75 & 1.0 \\
\hline TDI in MCB & 2240 & 50 & 395 for $1 \%(\mathrm{~m} / \mathrm{m})$ & 395 & 51.0 \\
\hline $\begin{array}{l}\text { Basonat in } \\
\text { propylene } \\
\text { carbonate }\end{array}$ & 2255 & 80 & 63 for $1 \%(\mathrm{~m} / \mathrm{m})$ & 63 & 8.1 \\
\hline Gaseous $\mathrm{CO}_{2}$ & $2338(2317)$ & $20(30)$ & 73 (69) for 4 bar & 18.25 & 2.35 \\
\hline
\end{tabular}

\section{Cylindrical Sensor Concept and Experimental Realization}

\subsection{Concept of a Future Process Instrument with a Cylindrical ATR Element}

As described in the introduction, an ATR probe for industrial processes has to have smooth and easy to clean surfaces. A seamless cylindrical surface would be favorable. Automatic liquid and vapor cleaning can be assisted by an adapted tube wiper ring. However, how to integrate such an element into a robust process probe? The basic idea of our project is to integrate a sapphire tube into a stainless-steel probe with negligible surface modification at the interface of the two materials. This probe shaft can be smoothly moved back and forth through suitable O-ring seals as shown in Figure 4. This movement can be considered as a first mechanical cleaning step. In a measurement position, the sapphire tube is exposed to the process medium. In a retracted position, the end cap of the shaft is sealing the port. In this position, the ATR element may be automatically cleaned and/or a recalibration may be performed in a cleaning chamber. In- and out-coupling of infrared radiation into the sapphire element is done from the inside of the tube. Additionally, a temperature sensor may be integrated into the sealing cap to measure the process temperature.

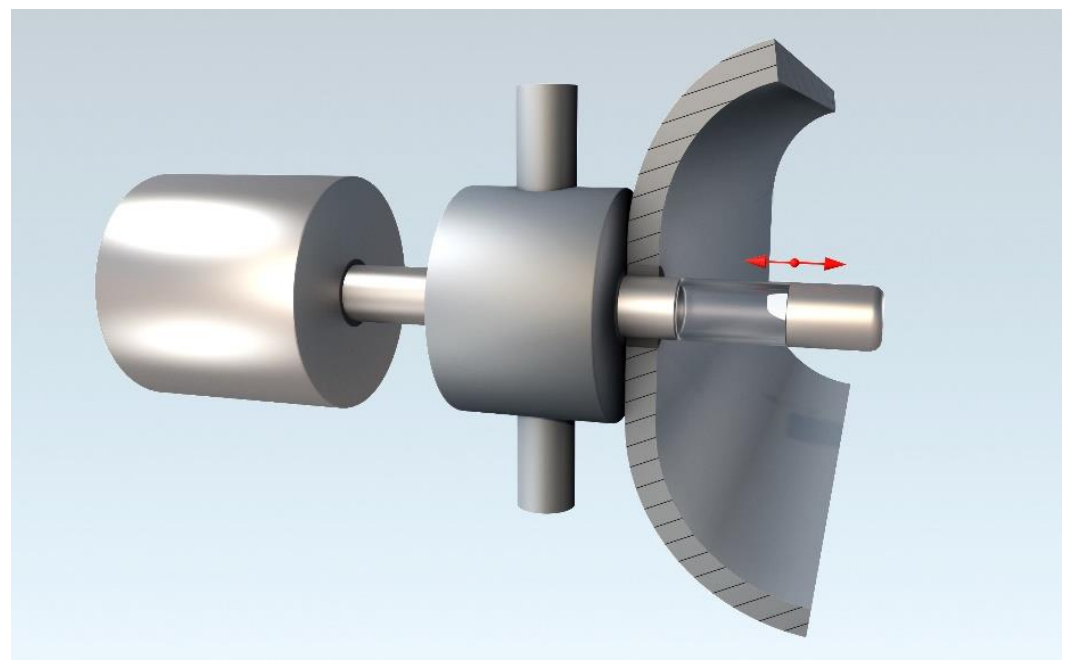

Figure 4. Concept view of a future process probe with a cylindrical ATR element. The probe consists of a tubular shaft with an integrated tubular sapphire ATR element. On one end of the shaft is the sensor control unit with signal processing and driver electronics, on the other end is a sealing cap. Between the process chamber and the control unit the shaft passes through a cleaning chamber. 


\subsection{Optical Simulation of Tubular ATR Configurations}

To investigate the feasibility of such a system, we focus here of the use of tubular ATR elements. Based on the experience with planar ATR sensors employing small thermal emitters and detectors (Section 2), it is obvious that sufficient infrared intensity at the detector entrance and enough suitable internal reflections at the outer surface of the ATR element are the key challenges of such a setup. Minimization of stray light influence is a further objective. Thus, extensive optical simulations using the ray tracing software Optic Studio 19 (Zemax Europe, Ltd., Stansted, UK) were performed to compare ATR elements of a tubular shape or of tube segments with those of a planar geometry and to optimize the positioning of the emitters and detector. The result is shown in Figure 5 for a sapphire tube with a wedged entrance side and an Au-coated reflector at the other side. Two infrared emitters are placed at the entrance and the detector is placed between them. The simulations show that only $\approx 1.8 \%$ of the radiation intensity of the two emitters entering the sapphire tube is detected by a LRM-254 detector placed between the two infrared emitters.

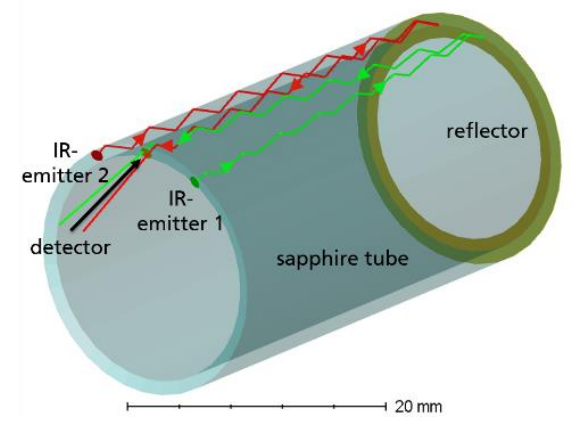

(a)

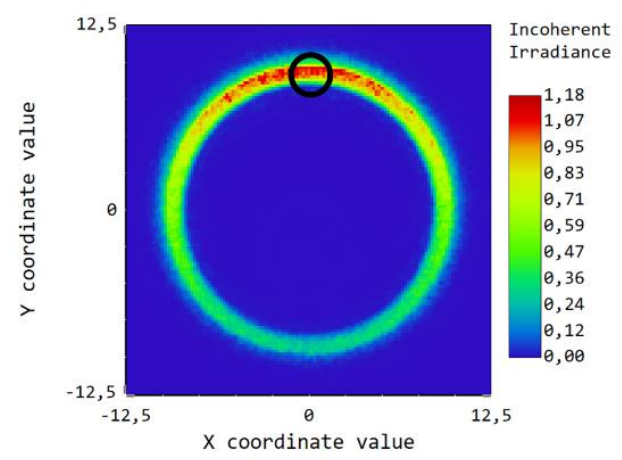

(b)

Figure 5. (a) Raytracing concept for a tubular ATR element with two infrared emitters placed at a wedged entrance side and a gold-coated reflector at the other side. (b): Simulated intensity distribution of the IR radiation, which is reflected from the mirror (direct reflections of the radiation from the first sapphire surface are not shown) on the entrance side. The black ring indicates the position of the IR detector. The false color scale on the right side describes in a. $u$. the irradiance on the exit area of the sapphire tube. The total exiting intensity is $\approx 26 \%$ of the entering intensity of the two emitters.

\subsection{Experimental Details}

Based on the optical simulations described above, cylindrical sapphire tubes of $40 \mathrm{~mm}$ length, $20 \mathrm{~mm}$ outer diameter, and $1 \mathrm{~mm}$ wall thickness were obtained from IMPEX HighTech GmbH, Rheine, Germany and a $69^{\circ}$ wedge was manufactured by grinding and optical polishing on one end of the tubes (Figure 6a). Some of the tubes were coated with a reflective Au layer on the other side of the tubes. By $90^{\circ}$ cutting, polishing, and subsequent Au coating of the sidewalls, a couple of segments of the sapphire tubes were prepared.

The sapphire tube was mounted between two Varivent flanges using O-ring seals (Figure 6b). This module can be mounted in a process flow cell using an outer pair of O-rings and can be pressurized up to 5 bar. For the ATR transmission experiments, three infrared emitters (JSIR350-5-BL-R-D3.6-2-A4, Micro-Hybrid Electronic $\mathrm{GmbH}$, Hermsdorf, Germany) were positioned at the $69^{\circ}$ wedge, with the emitter in the middle located just opposite the infrared detector, with integrated filters (Table 1 ) on the other side of the tube. For the ATR reflection experiments, two emitters were used, and the infrared detector was positioned between the emitters close to the wedged rim of the sapphire tube. 


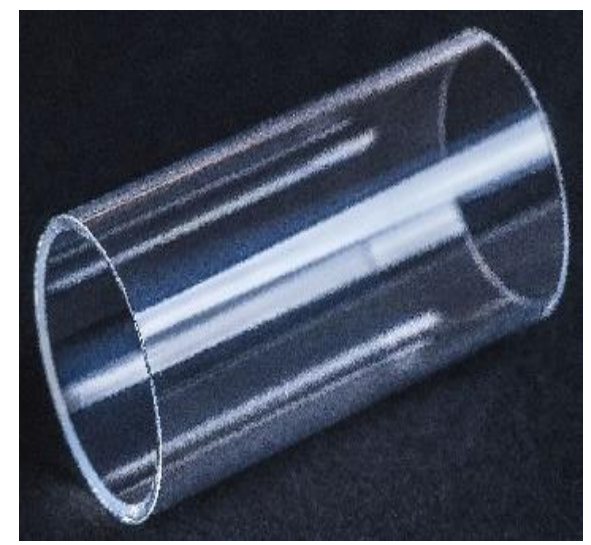

(a)

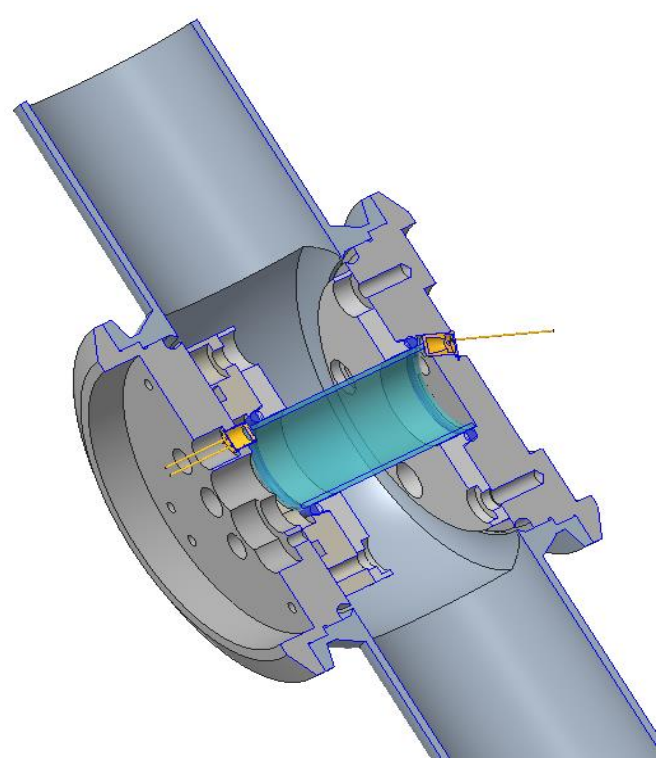

(b)

Figure 6. (a) Sapphire tube with the $69^{\circ}$ wedge on one side. (b) Schematic drawing of the mounted ATR element in a flow tube setup with one inclined IR emitter at the right side and one IR detector at the left side of the tube for the ATR transmission experiment.

\section{Experimental Results with Cylindrical ATR Elements}

\subsection{ATR Setup in Transmission Geometry}

\subsection{1. $\mathrm{CO}_{2}$ Pressure Steps}

To obtain a first impression of the sensor performance and check for leaks, the flow tube of Figure $6 \mathrm{~b}$ was pressurized with pure $\mathrm{CO}_{2}$ gas. The sealed inner part of the sapphire tube was previously filled with dry $\mathrm{N}_{2}$. The $\mathrm{CO}_{2}$ pressure can be rapidly changed and was varied in steps from 5 bar absolute pressure to ambient pressure (Figure 7). For this experiment, an LRM-202 detector with a suitable filter (Table 1) was employed, which fits well to the $\mathrm{CO}_{2}$ absorption band (Figure 3b). In the absorbance plot (Figure 7 bottom), the pressure steps are well resolved, and the absorbance value for a purge flow of $\mathrm{N}_{2}$ at ambient pressure is constant for $20 \mathrm{~h}$. Due to the good stability of the measurement, noise is efficiently reduced by a 1-min moving average. 

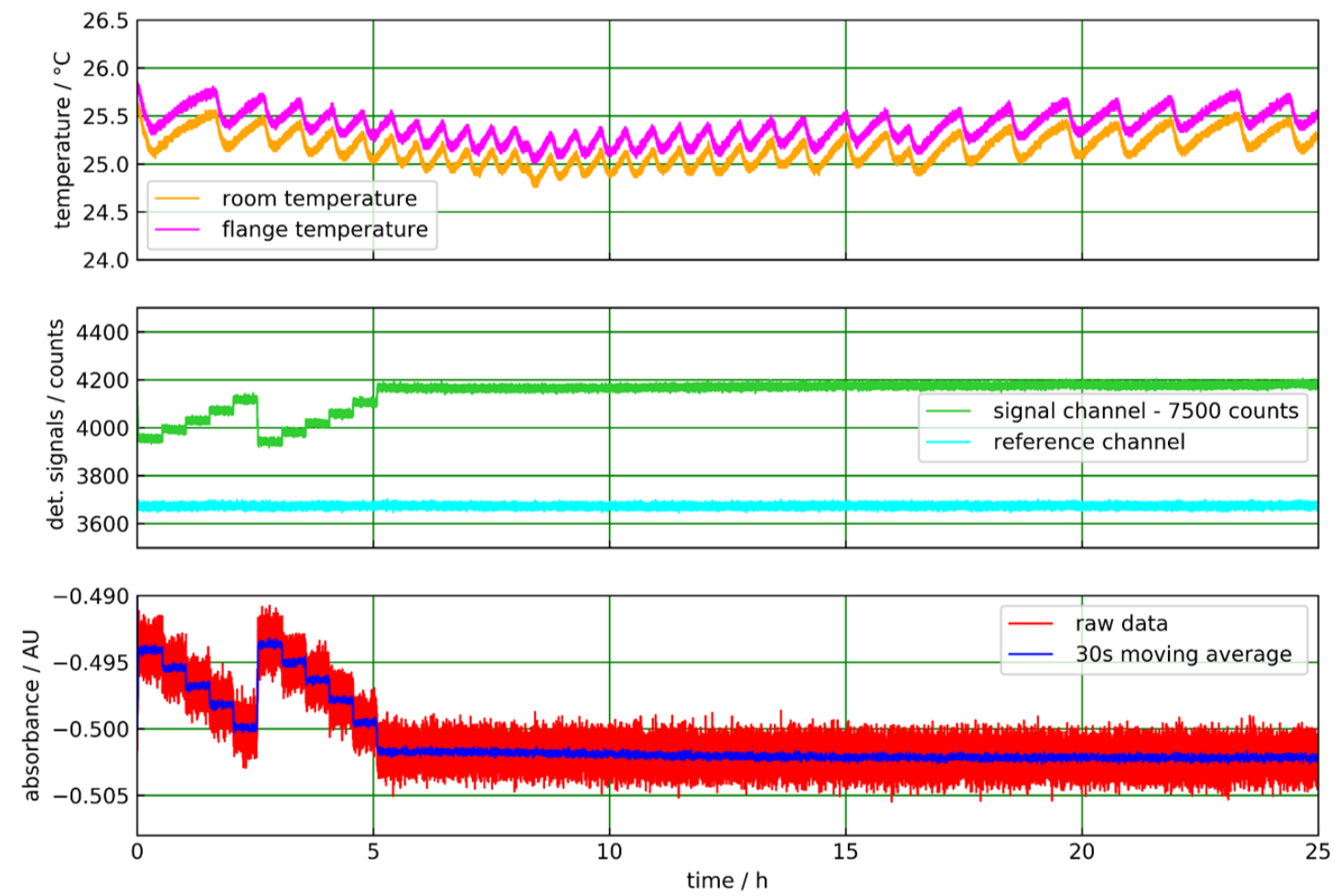

Figure 7. ATR measurement of pure $\mathrm{CO}_{2}$ gas with the sapphire tube in transmission geometry (Figure $6 \mathrm{~b}$ ). Ambient and flange temperatures show a sawtooth-like modulation between 25 and $26{ }^{\circ} \mathrm{C}$, which is caused by the lab temperature control. (top). The detector signal channel (middle) shows characteristic steps when the $\mathrm{CO}_{2}$ pressure is varied in 1-bar steps from 5 bar absolute pressure to ambient pressure. After $5 \mathrm{~h}$, a purge flow of $\mathrm{N}_{2}$ at ambient pressure sets in. The reference channel is not affected by the pressure variations and stays almost constant. In the absorbance plot the pressure steps are well resolved (bottom).

\subsubsection{Acetonitrile in Isopropanol Solutions}

The results of the continuous measurement of solutions of acetonitrile in isopropanol for more than $30 \mathrm{~h}$ is shown in Figure 8. The solutions are continuously pumped through the abovementioned flow cell with a peristaltic pump at a constant flow rate of approximately $200 \mathrm{~mL} / \mathrm{min}$ in a closed loop. For the concentration steps, defined amounts of acetonitrile are added to the isopropanol solvent into a liquid reservoir within the liquid flow cycle. The temperature of the liquid reservoir stabilized between 20 and $26^{\circ} \mathrm{C}$. One sensor measures the temperature of the Varivent flange. Another sensor measures the lab temperature in the vicinity of the flange. When adding liquid to the reservoir, the temperature of the flange is changed, and the room temperature value is also affected (Figure 8 (top)).

In this experiment, we employed an infrared detector equipped with a filter, which fits better to the acetonitrile absorption peak in Figure $3 \mathbf{b}$ (Table 1). In the absorbance plot (Figure 8 bottom), the concentration steps are well resolved, and the absorbance value for the pure solvent is almost constant for the initial $15 \mathrm{~h}$. Due to this good stability, noise is efficiently reduced by a 1-min moving average. A slight nonlinear response is found in the absorbance steps, i.e., the absorbance changes for relative $5 \%(\mathrm{~m} / \mathrm{m})$ steps of the acetonitrile concentration decrease with an increasing concentration. Such behavior was also observed for the ATR measurements of Basonat and TDI in [22]. 

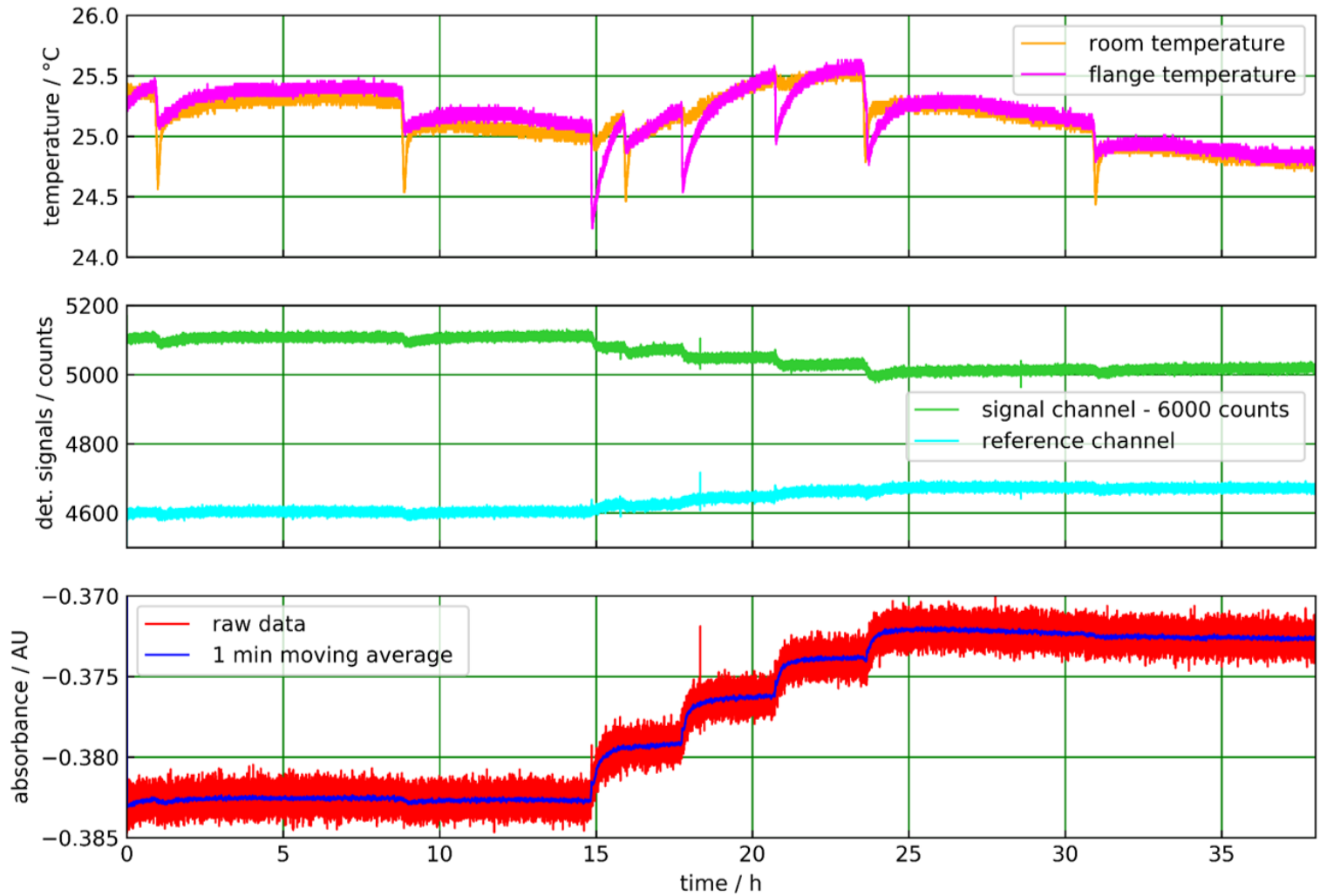

Figure 8. ATR measurement of acetonitrile in isopropanol with the sapphire tube in transmission geometry. The ambient and flange temperatures show distinct dips, which occurred when liquid was added to the sample reservoir (top). The signal and reference channel data are slightly affected by these events. Concentration steps $(0 \%, 5 \%, 10 \%, 15 \%, 20 \%(\mathrm{~m} / \mathrm{m})$ acetonitrile in isopropanol) are clearly visible in the signal channel but also in the reference channel, which shows an increasing level at higher acetonitrile concentrations (middle). In the absorbance plot the concentration steps are clearly resolved (bottom).

\subsection{ATR Setup in Reflection Geometry}

\subsection{1. $\mathrm{CO}_{2}$ Pressure Steps}

With the reflection setup, a $\mathrm{CO}_{2}$ experiment was also performed first and was pressurized with pure $\mathrm{CO}_{2}$ gas. The sealed inner part of the sapphire tube was previously filled with dry $\mathrm{N}_{2}$. The $\mathrm{CO}_{2}$ pressure was varied in steps from 5 bar absolute to ambient pressure (Figure 9) several times for more than $40 \mathrm{~h}$. For this experiment, the same detector as for the corresponding transmission experiment was employed (Table 1). In contrast to the transmission geometry, the detected power in the signal channel is lower than in the reference channel. The reason is that the optical path is longer for the reflection setup and the infrared absorption of sapphire is higher at the signal wavelength. The signal and reference channel raw data are much noisier than the transmission data. This is caused by the lower infrared intensity at the detector for the reflection setup compared with the transmission geometry. However, in the absorbance plot (Figure 9 bottom), the pressure steps can be well resolved when a 1-min moving average is employed. Due to the good stability of the measurement, even longer integration times may be applied depending on the application. 

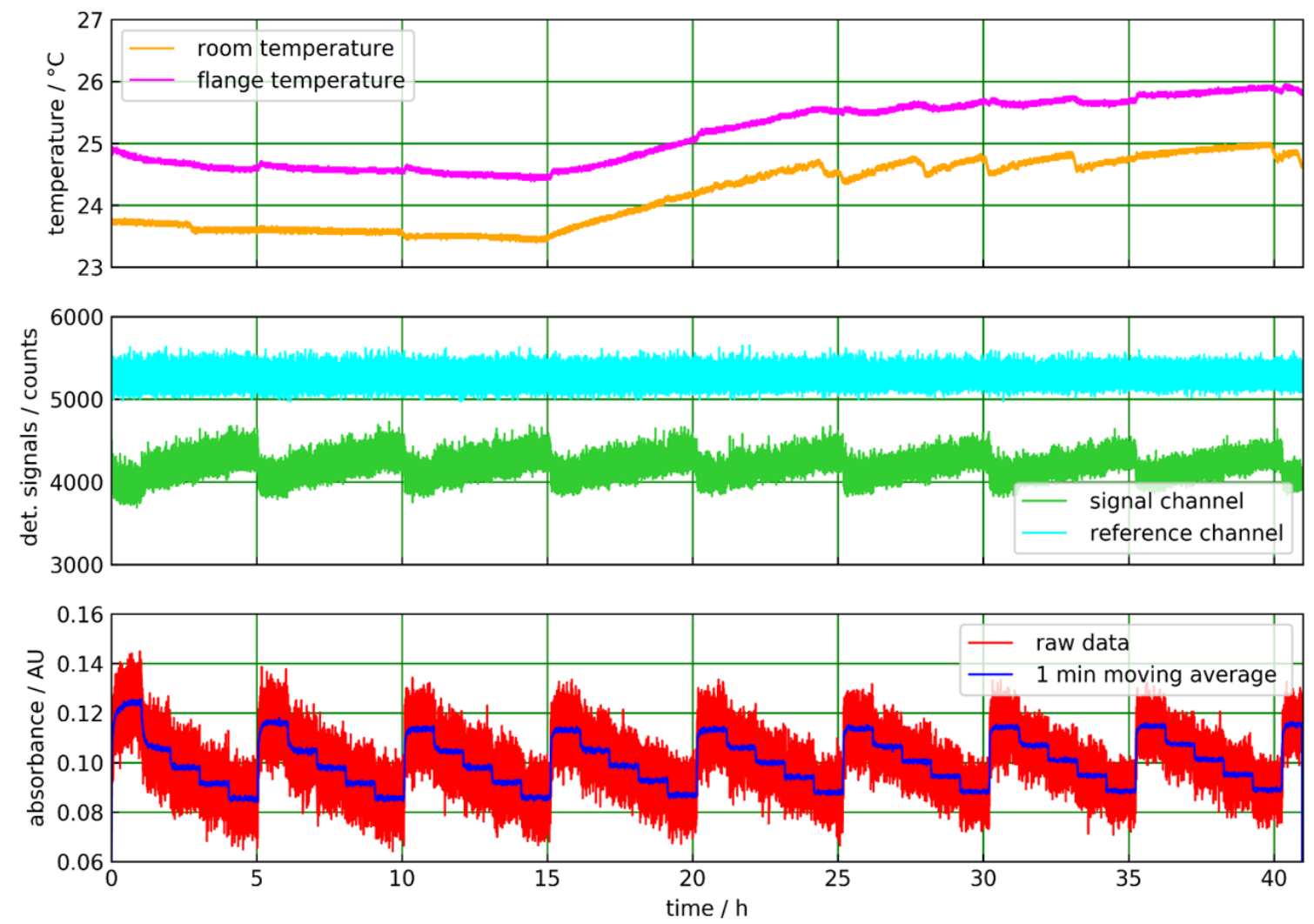

Figure 9. ATR measurement of pure $\mathrm{CO}_{2}$ gas with the sapphire tube in reflection geometry. Ambient and flange temperatures are shown in the (top) part. The detector signal channel shows characteristic steps when the $\mathrm{CO}_{2}$ pressure is varied in 1-bar steps from 5 bar absolute to ambient pressure. The reference channel is not affected by the pressure variations and stays constant (middle). In the absorbance plot the pressure steps are clearly resolved by a 1-min moving average (bottom).

\subsubsection{Acetonitril in Isopropanol Solutions}

The experiment was performed in a similar way as with the transmission setup, again using the LRM-254 detector with the previous filter combination (Table 1). In the absorbance plot (Figure 10 bottom), the concentration steps are well resolved, especially when averaging over $1 \mathrm{~min}$, and the absorbance value for pure solvent is almost constant for the initial $17 \mathrm{~h}$. Additionally, the value for $10 \%(\mathrm{~m} / \mathrm{m})$ acetonitrile is almost constant and reproducible for two time intervals of more than $15 \mathrm{~h}$. The mentioned nonlinearity is smaller than in the transmission setup. 

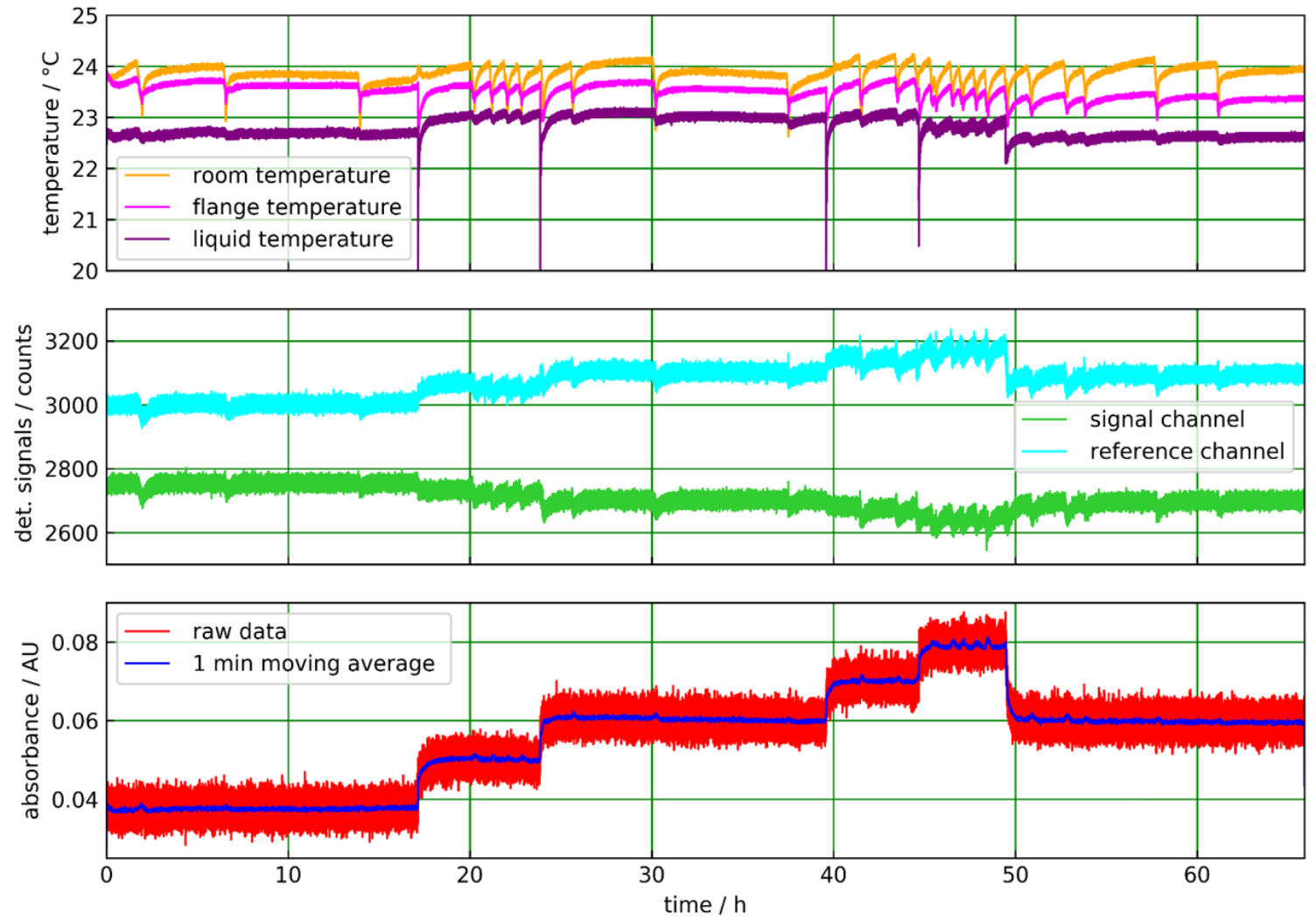

Figure 10. ATR measurement of acetonitrile in isopropanol with the sapphire tube in reflection geometry. Ambient and flange temperatures show distinct dips, which occurred when some liquid was added to the sample reservoir (top). The signal and reference channel data are hardly affected by these events. The concentration steps $(0 \%, 5 \%, 10 \%, 15 \%, 20 \%(\mathrm{~m} / \mathrm{m})$ acetonitrile in isopropanol) are clearly visible in the signal channel but also in the reference channel, which shows an increasing level at higher acetonitrile concentrations (middle). In the absorbance plot the concentration steps are clearly resolved. Noise is efficiently reduced by a 1-min moving average (bottom).

\section{Discussion}

We showed that ATR measurements on liquids and gases can be performed using tubular ATR elements and compact thermal sources and infrared detectors. Here, we analyzed and compared the signals and noise features of the different setups in more detail. For this purpose, we calculated the Allan deviations of the baseline signals of the $\mathrm{CO}_{2}$ and acetonitrile measurements of Section 4 . The Allan deviation was first introduced by Allan et al. to describe the statistical uncertainty of atomic frequency standards [23]. When taking a series of measurements of, e.g., the frequency of a clock, the Allan deviation $\sigma_{\mathrm{A}}$ of the frequency first decreases with increasing integration time $\tau$ (or number of averaged consecutive observations) because the noise averages out. For long integration times, the Allan deviation increases again due to various drift factors. This concept was later applied by Werle et al. [24] to describe the stability of laser spectrometers and now is generally used to describe the performance of various measurement systems.

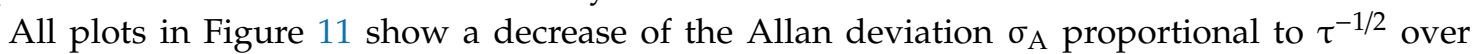
more than 2 decades of the integration time $\tau$. This is typical for white noise. The Allan minimum, indicating the averaging time $\tau_{\min }$ for the lowest $\sigma_{\mathrm{A}}$ value, is reached at roughly one hour for the $\mathrm{CO}_{2}$ measurements and between 5 and $10 \mathrm{~min}$ for the liquid measurements. For longer integration times, $\sigma_{\mathrm{A}}$ is increasing due to drift. However, even at the longest integration times, the corresponding $\sigma_{\mathrm{A}}$ is not considerably exceeding the values for an integration time $\tau$ of $1 \mathrm{~min}$, which are used in Figures 7-10, in [22], and listed in Table 3. Depending on the application, longer integration times 
of several minutes are an option for further noise reduction. Overall, the data demonstrate a high stability of the measurements.

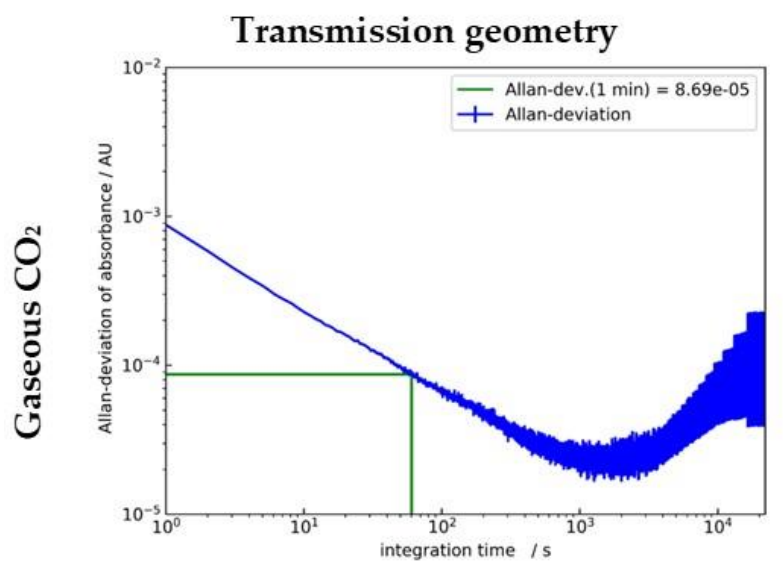

(a)

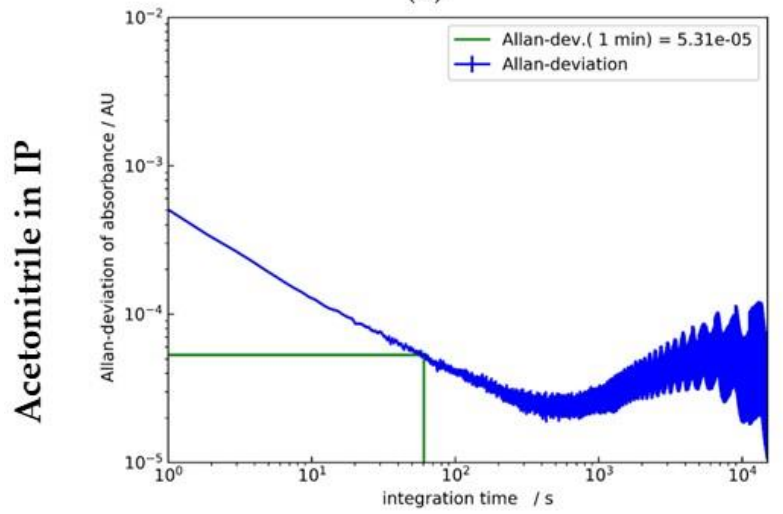

(c)

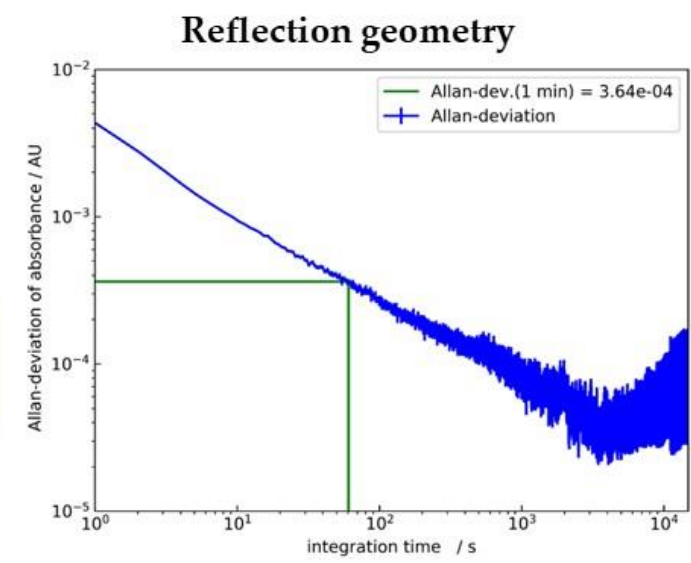

(b)

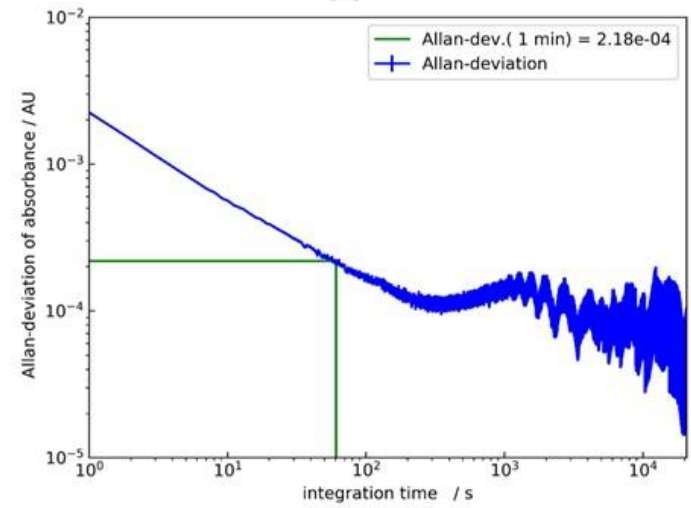

(d)

Figure 11. Allan deviation plots for ATR measurements with sapphire tubes. (a): $\mathrm{CO}_{2}$ pressure steps transmission setup; (b): $\mathrm{CO}_{2}$ pressure steps reflection setup; (c): acetonitrile in the isopropanol transmission setup; (d): acetonitrile in the isopropanol reflection setup. Allan deviations for an averaging time of $1 \mathrm{~min}$ were determined from the plots as indicated.

Table 3. Analysis of the ATR experiments with sapphire tubes. NEC ( $1 \sigma)$-values for Basonat respectively TDI are estimated using the conversion factors from Table 2.

\begin{tabular}{|c|c|c|c|c|}
\hline Sample & $\begin{array}{c}\text { Absorbance Change for } \\
1 \%(\mathrm{~m} / \mathrm{m}) \text { Solution } \\
\text { Resp. } 1 \mathrm{Bar} \mathrm{CO}_{2} \\
\text { Pressure Step } / \mathrm{mAU})\end{array}$ & $\begin{array}{l}\text { Allan Deviation } \\
\sigma_{A}(1 \mathrm{~min}) / \mathrm{mAU}\end{array}$ & $\begin{array}{l}\text { NEC }(1 \sigma) / p p m \\
(\mathrm{~m} / \mathrm{m}) \text { resp. mbar }\end{array}$ & $\begin{array}{c}\text { Estimated NEC for } \\
\text { Basonat/TDI/ } \\
\text { ppm (m/m) }\end{array}$ \\
\hline & \multicolumn{4}{|c|}{ Transmission } \\
\hline $\begin{array}{l}\text { Acetonitrile in } \\
\text { isopropanol }\end{array}$ & 0.68 & 0.053 & 780 & $96 / 15$ \\
\hline \multirow[t]{2}{*}{ Gaseous $\mathrm{CO}_{2}$} & 1.85 & 0.087 & 47 mbar & $136 / 22$ \\
\hline & \multicolumn{4}{|c|}{ Reflection } \\
\hline $\begin{array}{l}\text { Acetonitrile in } \\
\text { isopropanol }\end{array}$ & 2.6 & 0.22 & 846 & $104 / 17$ \\
\hline Gaseous $\mathrm{CO}_{2}$ & 6.63 & 0.36 & 54 mbar & $157 / 25$ \\
\hline
\end{tabular}

If we compare $\sigma_{\mathrm{A}}(1 \mathrm{~min})$ for $\mathrm{CO}_{2}$ and acetonitrile, the values for the liquid measurements are somewhat lower than for $\mathrm{CO}_{2}$, probably due to the different indices of refraction and detector types. Comparing transmission and reflection, it is obvious that $\sigma_{\mathrm{A}}$ for the transmission measurements is 
lower by a factor of $\approx 4.1$ because of the lower infrared radiation intensity at the detector for the reflection setup.

Table 3 shows the absorbance changes for the $1 \%(\mathrm{~m} / \mathrm{m})$ acetonitrile solution respectively 1-bar $\mathrm{CO}_{2}$ pressure steps for the transmission and reflection setups obtained from Figures 7-10. The absorbance changes for the reflection setup are a factor of $\approx 3.7$ higher than for the transmission setup, but this is compensated by lower Allan deviations. As a result, the NEC $(1 \sigma)$ values for reflection are only approximately $10 \%$ higher than for transmission. This indicates that the effective number of reflections is almost twice the transmission value, despite the strong divergence and scattering effects in the tubular geometry. The NEC $(1 \sigma)$ figures suggest, that acetonitrile concentrations of $1000 \mathrm{ppm}(\mathrm{m} / \mathrm{m})$ or $\mathrm{CO}_{2}$ pressure changes of $\approx 50$ mbar could be detected with both setups. Doubling these values is a more realistic estimate for the achievable limits of detection (LOD).

The NEC $(1 \sigma)$ values for the planar photometer setups in Table 4 are quite similar to the data for the cylindrical geometries, keeping in mind that conversions and digitization may introduce some uncertainties. The FPI measurement gave a substantially lower NEC $(1 \sigma)$ value for Basonat. This is partly due to the longer averaging time but may also result from the more advanced spectral evaluation. Future experiments with the cylindrical ATR setups and FPI detectors may clarify this point.

Table 4. Data of ATR transmission experiments with sapphire plates.

\begin{tabular}{|c|c|c|c|}
\hline Sample & $\begin{array}{l}\text { Absorbance } \\
\text { Change/mAU }\end{array}$ & $\begin{array}{c}\text { Standard Deviation } \\
\text { (Averaging Time } \\
\tau \text { )/mAU }\end{array}$ & $\operatorname{NEC}(1 \sigma) / \mathrm{ppm}(\mathrm{m} / \mathrm{m})$ \\
\hline $\begin{array}{l}\text { Basonat in propylene } \\
\text { carbonate (photometer) } \\
\text { Digitized data from [22] }\end{array}$ & $7.05(4600 \mathrm{ppm}(\mathrm{m} / \mathrm{m}))$ & $0.14(1 \mathrm{~min})$ & 91 \\
\hline $\begin{array}{c}\text { TDI in MCB } \\
\text { (photometer) } \\
\text { Digitized data from [22] }\end{array}$ & $3.7(100 \mathrm{ppm}(\mathrm{m} / \mathrm{m}))$ & $1.7(1 \mathrm{~min})$ & 46 \\
\hline $\begin{array}{l}\text { Basonat in propylene } \\
\text { carbonate (FPI) } \\
\text { (s. chapter 2) }\end{array}$ & $1(100$ ppm $(\mathrm{m} / \mathrm{m}))$ & $0.25(2.5 \mathrm{~min})$ & 25 \\
\hline
\end{tabular}

\section{Conclusions and Outlook}

Compared to common ATR probes, which are using sapphire or diamond prism [6,14-16] tips with 2-3 reflections or a diamond plate as a chemically resistant ATR window attached to a ZnSe crystal (1 reflection) [25], planar ATR elements have a higher sensitivity due to more reflections. With this setup, an isocyanate concentration below $100 \mathrm{ppm}(\mathrm{m} / \mathrm{m})$ can be determined [22]. In this work we showed that sensitive IR-ATR sensors can be realized using sapphire tubes as cylindrical ATR elements. With such elements, having a comparable length to usual planar ATR crystals, similar detection limits can be achieved for transmission and reflection setups. Isocyanate solutions with concentrations below $100 \mathrm{ppm}(\mathrm{m} / \mathrm{m})$ can be detected with a photometer device. Cylindrical ATR sensors have a smooth and easy to clean surface, will be suitable for CIP procedures, and can be incorporated into a process flow similar to Figure 6, e.g., in an online bypass configuration.

In an alternative configuration to Figure 6, the process medium may flow inside of the sapphire tube. Although this would require several changes of the mechanical construction, similar results are expected when the inner side of the tube serves as the active ATR surface. Easy cleaning of the inner side of a sapphire tube is also possible.

Furthermore, such sapphire tubes could be incorporated into a process probe with an automatic cleaning system as shown schematically in Figure 4. However, for this purpose, a seamless integration of the sapphire tube into a stainless-steel shaft and an efficient coupling of the infrared emitter and detector elements have to be realized. For most industrial applications, such a probe has to comply with safety regulations (e.g., explosion prevention) and has to withstand temperatures up to $200^{\circ} \mathrm{C}$. Thus, 
infrared emitters and the detector may not be attached directly to the sapphire tube and additional light guides will be required. Coupling of sufficient infrared radiation into the sapphire tube is even more challenging for a process probe.

First, experiments with sapphire segments (Section 4) indicated that compared to the tubes, similar results were obtained with less incident power, and a higher radiation throughput can be achieved. This may facilitate coupling at the expense of a more complex mechanical integration.

All limitations by low radiation intensities will be overcome by novel MIR laser sources. They offer a huge intensity increase compared to thermal light sources, which are fundamentally limited by Planck's law. Recently, real-time reaction monitoring using ATR spectroscopy with a dual comb spectrometer was demonstrated [26]. Although still a rather expensive and bulky approach, the combination of rugged cylindrical ATR probes and such light sources will enable new process analytical applications.

Author Contributions: Conceptualization, A.L. and G.S.; Formal analysis, A.L. and C.B.; Investigation, J.E., H.F. and G.S.; Methodology, A.L. and G.S.; Project administration, G.S.; Resources, J.E. and H.F.; Software, C.B.; Writing-original draft, A.L. All authors have read and agreed to the submitted version of the manuscript.

Funding: This work was funded by the German ministry of education and research (BMBF), grant No. FKZ 13N14188.

Acknowledgments: Special thanks to InfraTec GmbH for supply and support regarding the infrared detectors and the FPI.

Conflicts of Interest: The authors declare no conflict of interest. The founding sponsors had no role in the design of the study; in the collection, analyses, or interpretation of data; in the writing of the manuscript, and in the decision to publish the results.

\section{References}

1. Harrick, N.J. Electric Field Strengths at Totally Reflecting Interfaces. J. Opt. Soc. Am. 1965, 55, 851. [CrossRef]

2. Harrick, N.J. Internal Reflection Spectroscopy; Interscience Publ: New York, NY, USA, 1967; ISBN 0-470-35250-7.

3. Heise, H.M.; Voigt, G.; Lampen, P.; Kupper, L.; Rudloff, S.; Werner, G. Multivariate Calibration for the Determination of Analytes in Urine Using Mid-Infrared Attenuated Total Reflection Spectroscopy. Appl. Spectrosc. 2001, 55, 434-443. [CrossRef]

4. Lambrecht, A.; Beyer, T.; Hebestreit, K.; Mischler, R.; Petrich, W. Continuous glucose monitoring by means of fiber-based, mid-infrared laser spectroscopy. Appl. Spectrosc. 2006, 60, 729-736. [CrossRef] [PubMed]

5. Su, W.-H.; Sun, D.-W. Mid-infrared (MIR) Spectroscopy for Quality Analysis of Liquid Foods. Food Eng. Rev. 2019, 11, 142-158. [CrossRef]

6. Anton Paar. Carbo 520 Optical. Available online: https://www.anton-paar.com/us-en/products/details/carbo520-optical/ (accessed on 16 March 2020).

7. Centec. CARBOTEC NIR. Available online: https://www.centec.de/sensors/electronics-semiconductor/ carbotec-nir/ (accessed on 16 March 2020).

8. Lu, R.; Mizaikoff, B.; Li, W.-W.; Qian, C.; Katzir, A.; Raichlin, Y.; Sheng, G.-P.; Yu, H.-Q. Determination of Chlorinated Hydrocarbons in Water Using Highly Sensitive Mid-Infrared Sensor Technology. Sci. Rep. 2013, 3, 1-6. [CrossRef] [PubMed]

9. Lambrecht, A.; Pfeifer, M.; Konz, W.; Herbst, J.; Axtmann, F. Broadband spectroscopy with external cavity quantum cascade lasers beyond conventional absorption measurements. Analyst 2014, 139, 2070-2078. [CrossRef] [PubMed]

10. Sim, S.F.; Jeffrey Kimura, A.L. Partial Least Squares (PLS) Integrated Fourier Transform Infrared (FTIR) Approach for Prediction of Moisture in Transformer Oil and Lubricating Oil. J. Spectrosc. 2019, 2019, 5916506. [CrossRef]

11. Helmdach, L.; Feth, M.P.; Minnich, C.; Ulrich, J. Application of ATR-MIR Spectroscopy in the Pilot Plant-Scope and Limitations Using the Example of Paracetamol Crystallizations. Available online: http: //www.sciencedirect.com/science/article/pii/S0255270113000913\# (accessed on 20 May 2020).

12. Dubé, M.A.; Li, L. In-Line Monitoring of SBR Emulsion Polymerization Using ATR-FTIR Spectroscopy. Polym. Plast. Technol. Eng. 2010, 49, 648-656. [CrossRef]

13. Specac Ltd. Golden Gate / Versatile ATR Accessory. Available online: https://www.specac.com/en/products/ ftir-acc/atr/atr/golden-gate (accessed on 17 March 2020). 
14. Hellma GmbH. DPR 207/DMD 270 ATR Small Diameter Probe. Available online: https://www.hellma.com/ en/process-analytics/process-probes/ir-products/ (accessed on 20 May 2020).

15. Art Photonics GmbH. Fiber Optic ATR-Probes. Available online: https://artphotonics.com/product/fiberoptic-atr-probes/ (accessed on 17 March 2020).

16. IFS GmbH. MIR Fiber Probes with Diamond ATR FTIR Technology. Available online: https://ifs-aachen.de/ (accessed on 17 March 2020).

17. Eccleston, R.; Wolf, C.; Balsam, M.; Schulte, F.; Bongards, M.; Rehorek, A. Mid-Infrared Spectroscopy for Monitoring of Anaerobic Digestion Processes-Prospects and Challenges. Chem. Eng. Technol. 2016, 39, 627-636. [CrossRef]

18. Baumgartner, B.; Freitag, S.; Gasser, C.; Lendl, B. A pocket-sized 3D-printed attenuated total reflection-infrared filtometer combined with functionalized silica films for nitrate sensing in water. Sens. Actuators B Chem. 2020, 310, 127847. [CrossRef]

19. Thomson, M.A.; Melling, P.J. Am Slepski. Real-time monitoring of isocyanate chemistry using a fiber-optic FTIR probe. Abstr. Pap. Am. Chem. Soc. 2001, 221, U316.

20. Friebe, A.; Siesler, H.W. In situ monitoring of an isocyanate reaction by fiber-optic FT-IR/ATR-spectroscopy. Vib. Spectrosc. 2007, 43, 217-220. [CrossRef]

21. The National Institute for Occupational Safety and Health. Toluene Diisocyanate (TDI) and Toluenediamine (TDA): Evidence of Carcinogenicity: Current Intelligence Bulletin 53. DHHS (NIOSH) Publication Number 90-101. Available online: https://www.cdc.gov/niosh/docs/90-101/default.html (accessed on 17 March 2020).

22. Theuer, M.; Hennig, S.; Ferstl, W.; Konz, W.; Lambrecht, A. ATR-Photometer zur Bestimmung der Isocyanatkonzentration in Prozessanwendungen. tm-Tech. Mess. 2015, 82, 16-23. [CrossRef]

23. Allan, D.W. Statistics of atomic frequency standards. Proc. IEEE 1966, 54, 221-230. [CrossRef]

24. Werle, P.; Mucke, R.; Slemr, F. The limits of signal averaging in atmospheric trace-gas monitoring by tunable diode-laser absorption-spectroscopy (Tdlas). Appl. Phys. B-Photophysics Laser Chem. 1993, 57, 131-139. [CrossRef]

25. Geoerg, D.; Schalk, R.; Methner, F.-J.; Beuermann, T. MIR-ATR sensor for process monitoring. Meas. Sci. Technol. 2015, 26, 065501. [CrossRef]

26. Herman, D.I.; Waxman, E.M.; Ycas, G.; Giorgetta, F.R.; Newbury, N.R.; Coddington, I.R. Real-time liquid-phase organic reaction monitoring with mid-infrared attenuated total reflectance dual frequency comb spectroscopy. J. Mol. Spectrosc. 2019, 356, 39-45. [CrossRef] 